\title{
علاقة الهدس في علم الجمال بعلم نفس الفن وتأثيره على عملية النقد التذوق الفني
}

\author{
إعلداد \\ د. وديعة بنت عبد|لله أحمد بوككر \\ أستاذ مساعد الرسم والتصوير \\ بجامعة الملك عبدالعزيز- كلية التصاميم والفنون
}

مجلة بحوث التربية النوعية - جامعة المنصورة

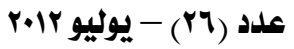




\section{علاقة الحدس في علم الجمال بعلم نفس الفن}

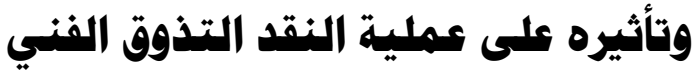

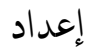

* ـ ـ وديعة بنت عبداللهّ أحمد بوكر

|ll|

بوكر، وديعة بنت عبدالله بن أحمد . علاقة الحدس ِِّ علم الجمال بعلهم نفس الفـن وتأثيره

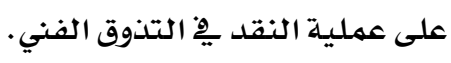

الهمدف:

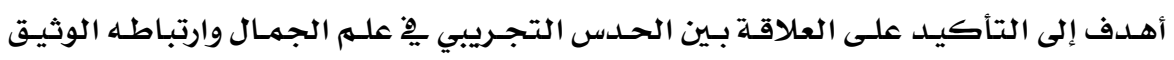

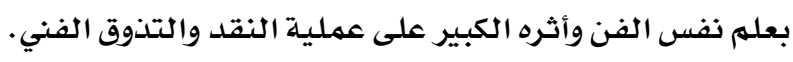

النتيجة العلمية:

توجد علاقة وثيقة بين الحدس يِّ علم الجمال وبين علم نفس الفن، بل ويوجد تأثير له على

$$
\text { عملية النقد والتذوق الفني. }
$$

الأهمية العلمية:

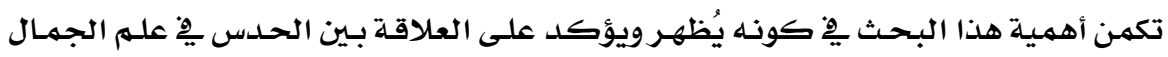

$$
\text { وعلم نفس الفن وأثره على عملية النقد والتذوق الفني. }
$$

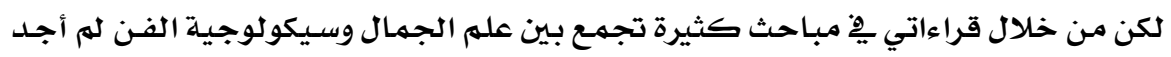

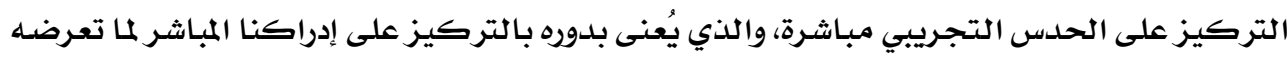

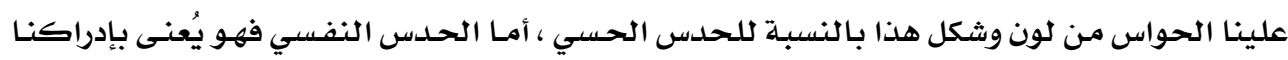

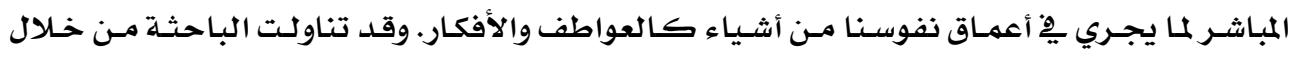

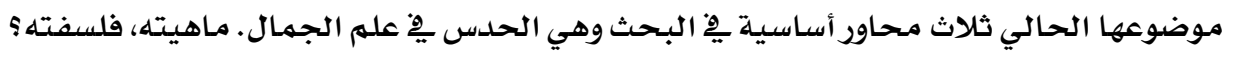
' ا . علم نفس الفن" سيكولوجية الفن" . وعلاقته بالحدس.

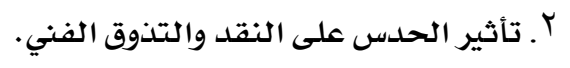

النتائج:

' ـ وجدت الباحثة أن الحدس هو وسيلة للكثف عن الرؤى الجمالية والصور الذهنية المتخيلة. Y . أن هناك علاقة وثيقة بين الحدس يِّ علهم الجمال وعلهم نفس الفن.

* أستاذ مساعد الرسم والتصوير بجامعة الملك عبدالعزيز- ـ كلية التصاميم والفنون 


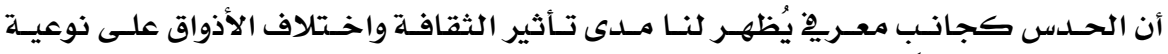
الاستجابة. ولكن الفن عموما على عكس مما نتخيل ، فهو فعل وتحقيق وليس مجرد حدس وتعبير. التوصيات:

ا ـ التركيز يِّتدريس المعايير والقضايا الجمالية التي لها صلة بالنقد الفني. r. أن الدراسـة الحالية من شأنها إفادة المشتغلـين بـالنقد والتذوق الفني. "؟. اتباع المنهج السيكولوجي والطرائق العلمية التجريبية إلى جانب الاعتماد على جانب المنهج الفلسفي والنقدي يوصل بالعمل إلى مرحلة الابداع الفني. 
The Relationship of Intuition in terms of Beauty and the Psychology of Art and its Impact on Art Critic

By: Wadeah Abdullah Ahmed Boker

Abstract

Objective: The objective of the Research is to reflect the empirical intuition in terms of beauty, its close relationship with the art and its strong impact on art critics.

Rational Scientific Result: There is a relationship between intuition in terms of beauty and the psychology of art; moreover, it has a great impact on art critics.

Scientific Importance: The importance of the Research is that the researcher depicts and affirms the relationship between intuition in terms of beauty and the psychology of art and its impact on critics. The scientific result, however, enables us to understand in depth the relationship between intuition in terms of beauty and the psychology of art critics, impact and comprehension.

Justifications of the Research: The Researcher, through extensive reading and study of various beauty papers, have realized that little was given to the relationship between intuition in terms of beauty; specially, the psychology of art and its impact. Taking into consideration the direct colors, forms, sensations that our senses gathers when we look into the beauty of arts, the Researcher have concentrated on the principal elements:

- Intuition in terms of beauty, characteristics and philosophy

- The psychology of art and its relationship with intuition

- The impact of intuition in art critics

Among the results, the Researcher found that intuition is the tool for exploring in depth the aspects of beauty mentally and imaginatively. Moreover, there is a close relationship between intuition in terms of beauty 
and art psychology. In other words, intuition various between an individual and another hence the appreciation of work varies among people.

\section{Recommendations:}

- It is imperative that technical standards and beauty aspects are to be taken more seriously.

- The current study can be effective tool for those who are concerned with critics and art appreciation.

Adoption of psychological methodology, empirical and scientific practices as well as philosophy of critic that enhance the value and creativity of artwork. 


\section{علاقة الحدس في علم الجمال بعلم نفس الفن}

وتأثيره على عملية النقد التذوق الفنبي

(إعداد

* ـ وديعةبنت عبداللهأحمد بوكر

الكلمات الإفتاحية للبحث

الحـدس: هـو كل معرفـة تأتينـا بـشكل مباشـروعفـوي ولا تحتـاج إلى عنـاء للحصـول عليها

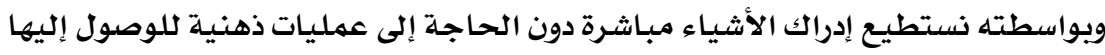

و أنواع الحلس هي : و

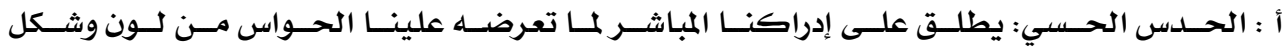

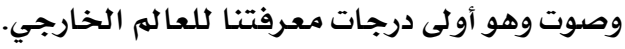

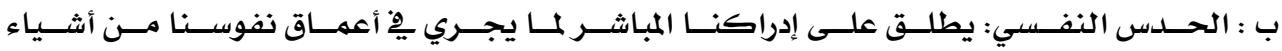
كالعواطف والأفكار والرغبات .ولا يمكن فصلهما عن بعض إلا من خلال موضوعهما

علم الجمال:

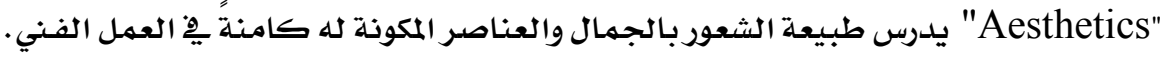

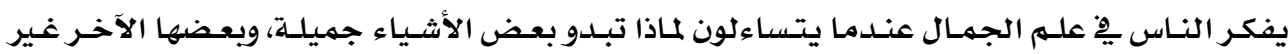

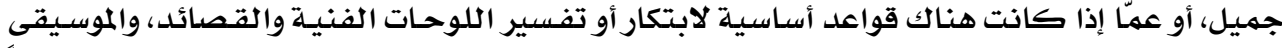

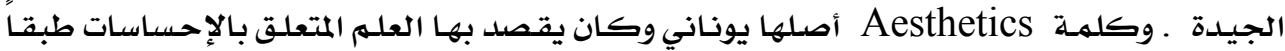

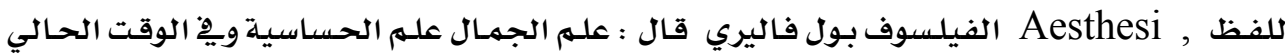

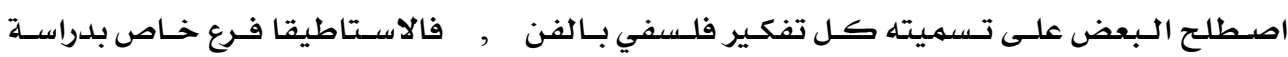
الحس والوجدان.

علم نفس الفز ( سيكولوجية الفن):

هو حقل متعدد التخصصـات لدراسـة الإدراك والخصائص الفنيـة وإنتاجـه لاستخدام مـواد الفن كشكل مـن أثكال العلاج النفسي · وكان لتيودور- وهو طبيب نفسي- اومقره ميـونيخ دورًا

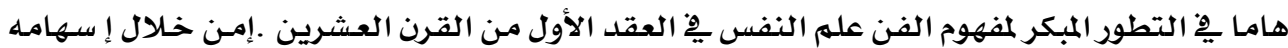

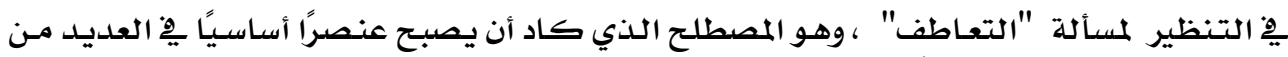

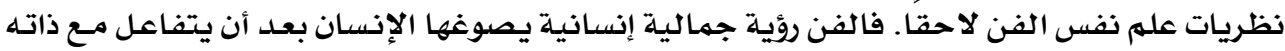

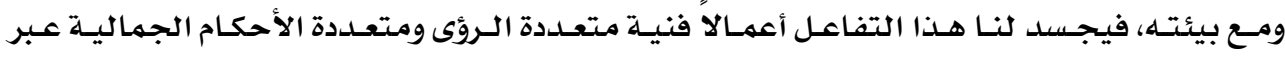

* أستاذ مساعد الرسم والتصوير بجامعة الملك عبدالعزيز- كلية التصاميم والفنون 


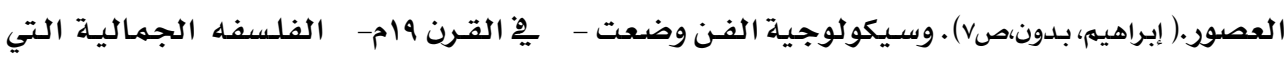

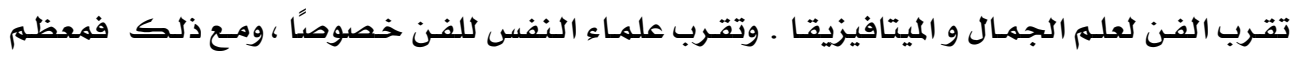

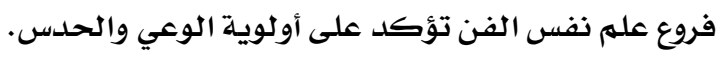
النقل الفني :

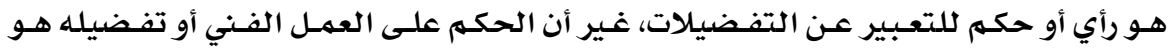

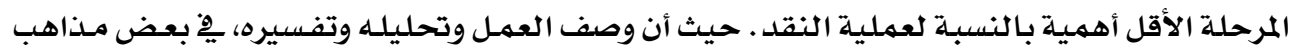

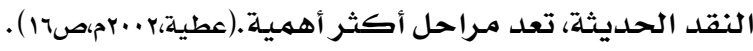

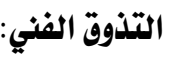

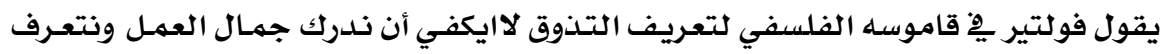

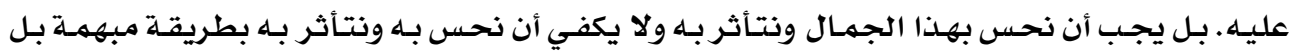

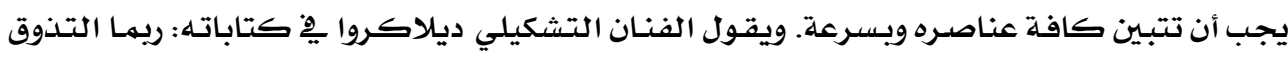

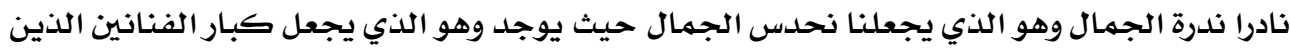

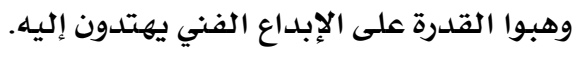

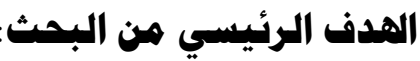

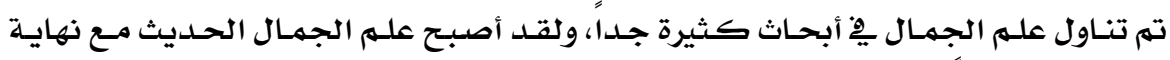

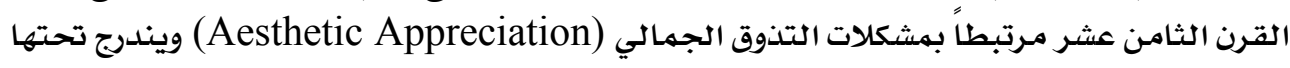

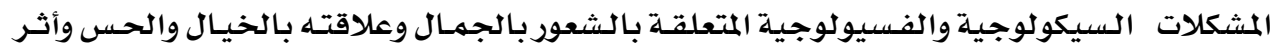

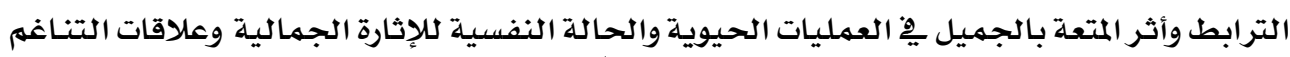

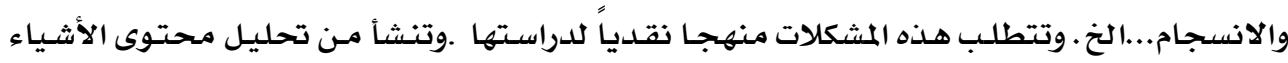

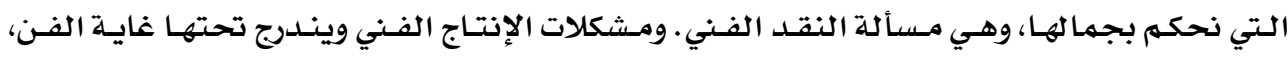

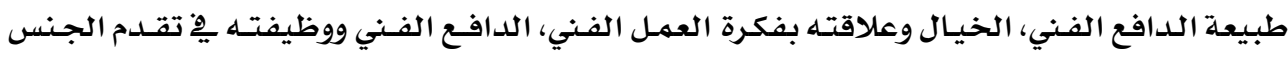

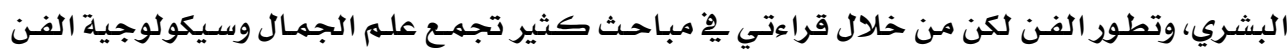

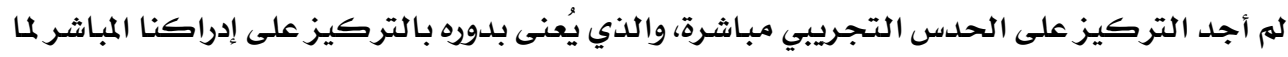

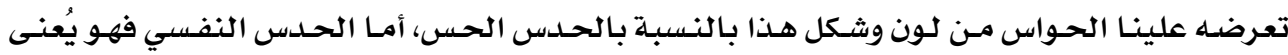

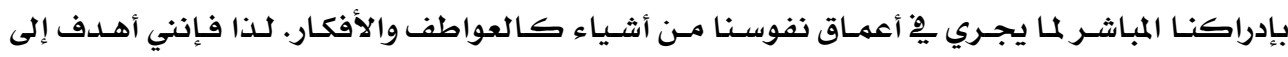

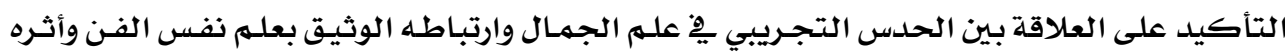
الكبير على عملية النقد والتذوق الفني التئي

النتيجة العلميية:

توجد علاقة وثيقة بين الحدس بِّ علم الجمال وبين علم نفس الفن، بل ويوجد تأثير له على عملية النقد والتذوق الفني. 


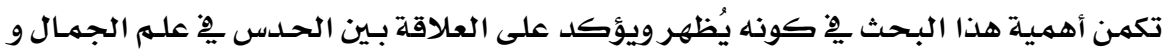

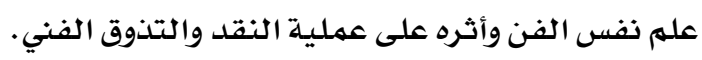

النتيجة التتوقعة:

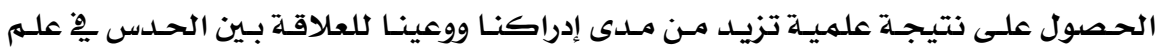

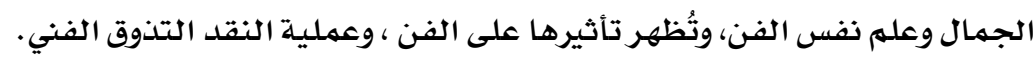

ا . تحليل وتفسير الحدس خاصدة يِّ علم الجمال، و الكشف عن منطلقاته الفكرية والفنية . ץ. التأكيد على العلاقة بين الحدس يِّ عله الجمال وارتباطه الوثيق بعله نفس الفن وأثره الكبير

$$
\text { على عملية النقد والتذوق الفني }
$$

\section{المدود الزمهانية والمكانية:}

يبدأ التتبـع التاريخي للحدس ِِّ علـم الجمـال وسـيكولوجية الفـن منـذ النشأة إلى المعاصـرة.

وارتباطهم بعملية النقد والتذوق الفني، مـع تحديد الفترات التاريخية المبكرة من ظهورهما.

أساليسب جمه البـيانات:

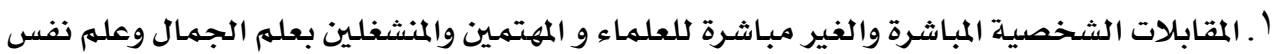

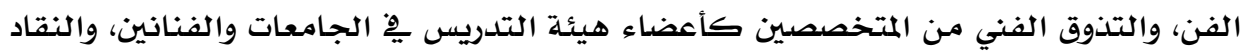

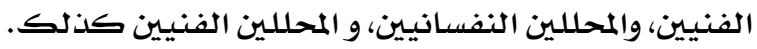

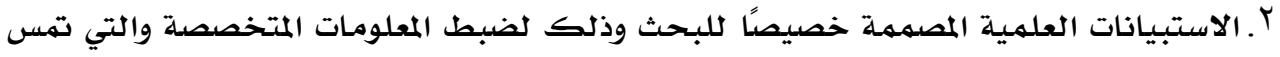

$$
\text { البحث مباشرة. }
$$

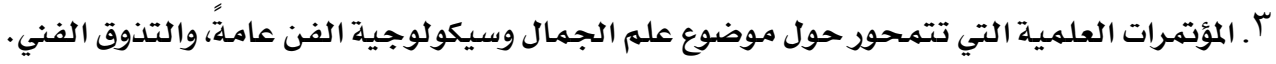

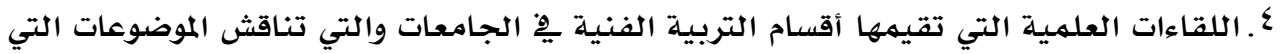

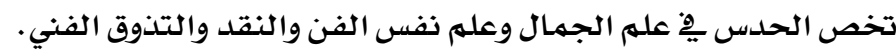

๑. الاطلاع على الرسائل العلمية التي تناولت الحدس ِِّ علم الجمال وسيكولوجية الفن والنقد

$$
\text { والتذوق الفني. }
$$

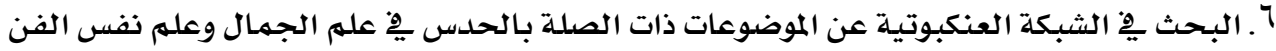

$$
\text { والنقد والتذوق الفني. }
$$

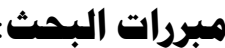

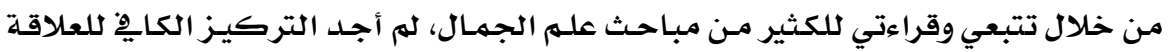

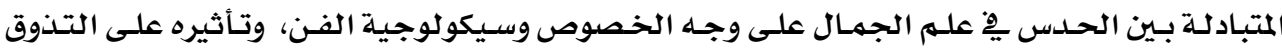




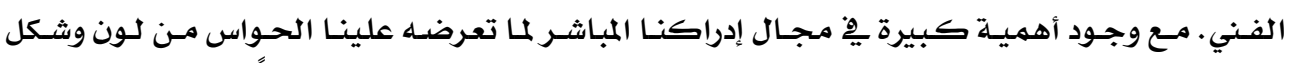

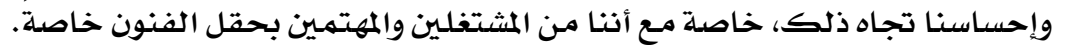
ستتناول الباحثة من خلالها موضوعها الحالي ثلاثة محاور أساسية في البحث وهي:

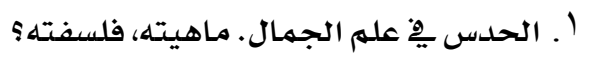

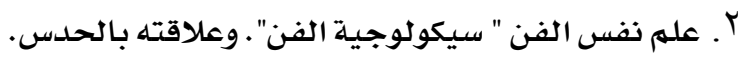

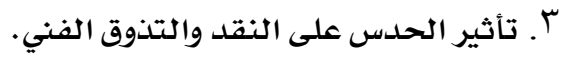

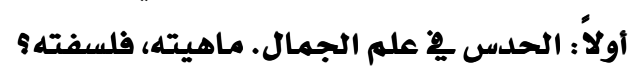

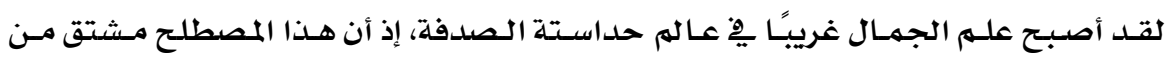

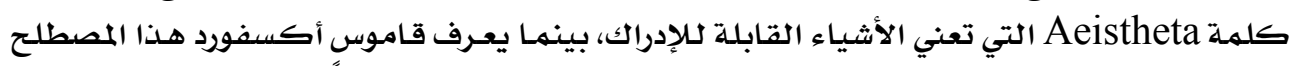

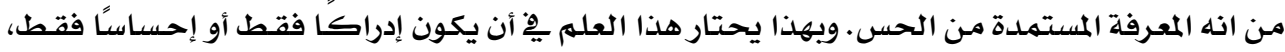

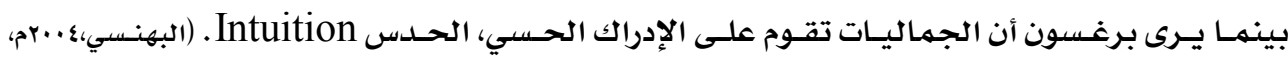

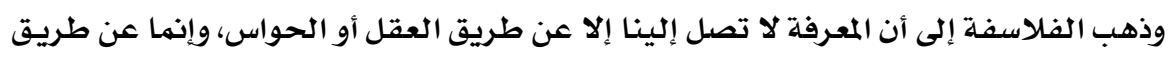

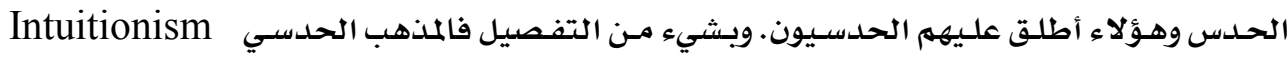

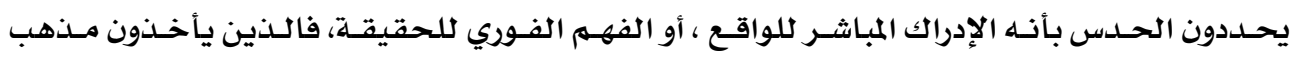

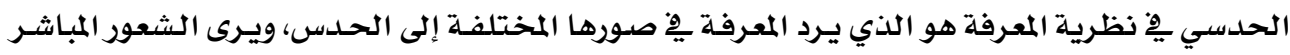

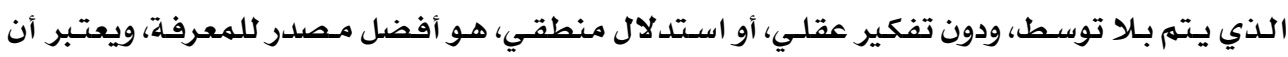

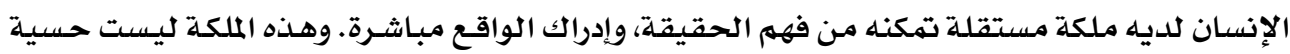

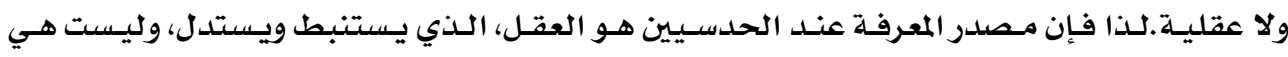

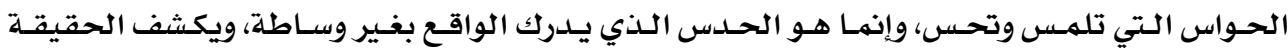

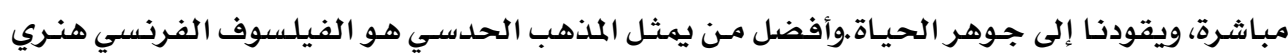

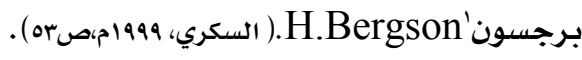

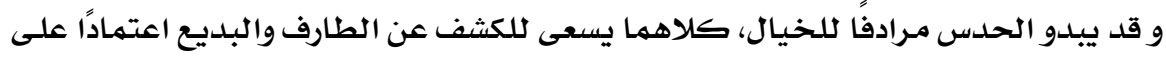

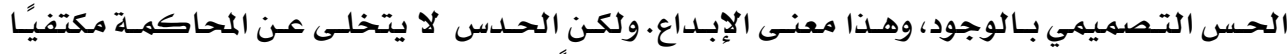

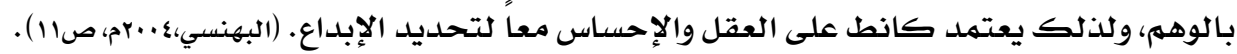

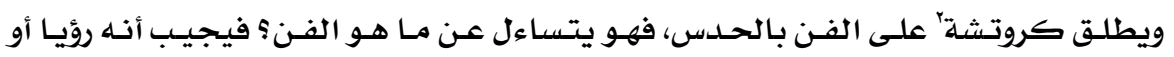

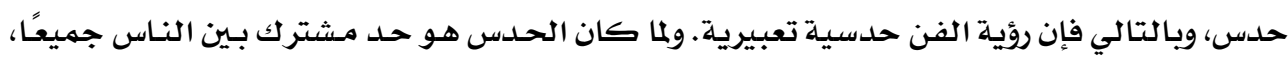

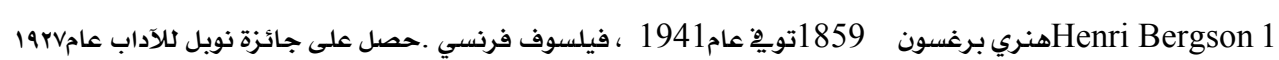

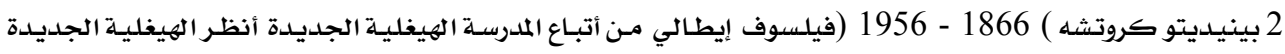

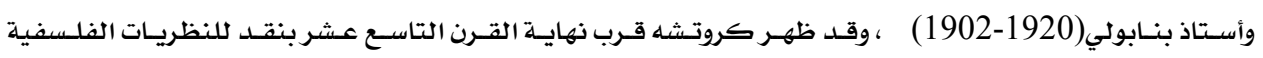




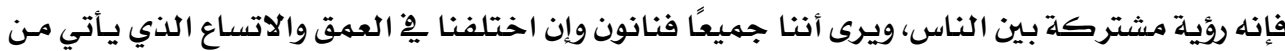

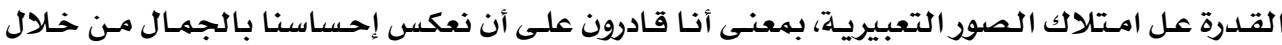

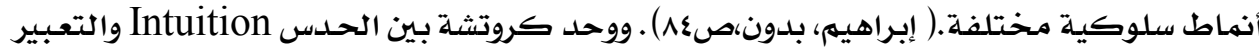
Expression

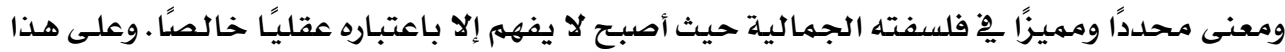

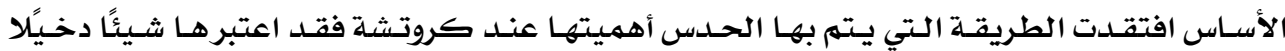

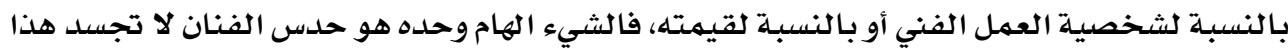

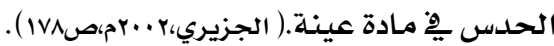

وقال كروتشة الايطالي و برغسونا الفرنسي أيضًا عن الحدس " ثمة معرفة تأتي عن طريق

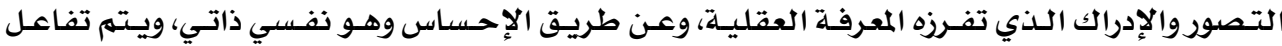

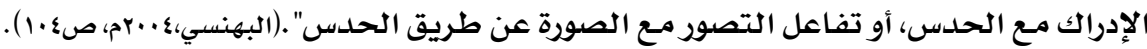
وقد ربط الكثير ما بـين الحدس ودوره يٌ عمليـة كعالم النفس " والاس

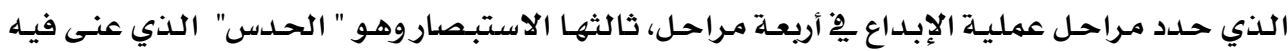

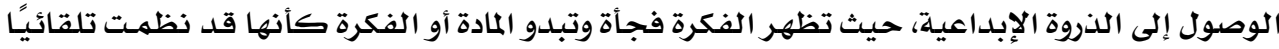

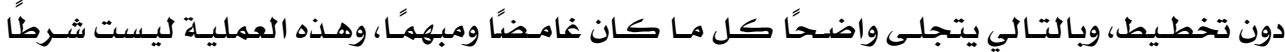

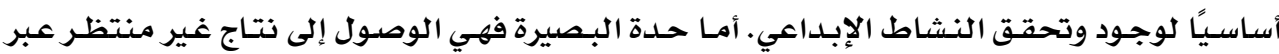
الفكر الثاقب.( علي، 1991م،صوrr). وإذا جئنا للظاهراتية أو الفينومينولوجيا هي مدرسة فلسفية تعتمد على الخبرة الحدسية

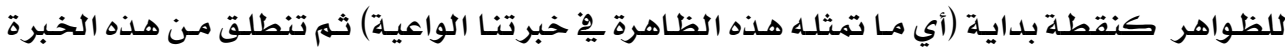

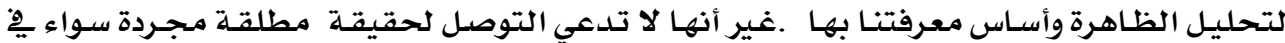

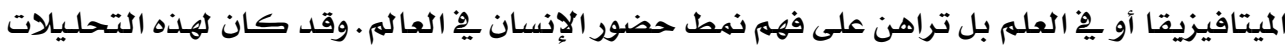

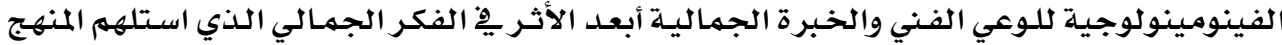

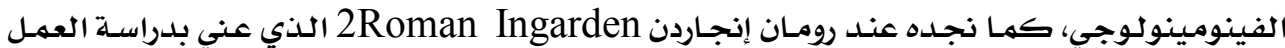

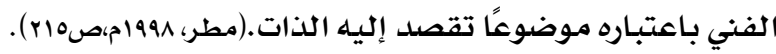

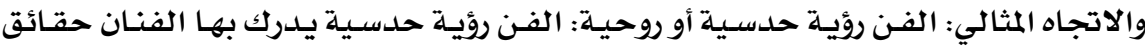

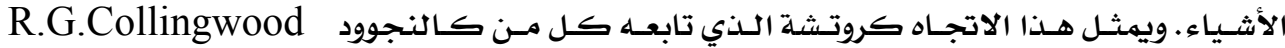

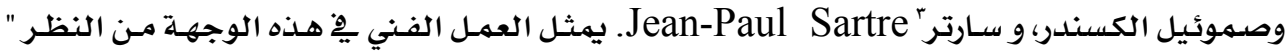
هنري برغسون 18أكتوبر 1859 - 4يناير .1941 فيلسوف فرنسي .حصل على جائزة نوبل 1

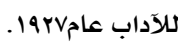

$$
2 \text { فيلسوف وناقد بولندي. }
$$

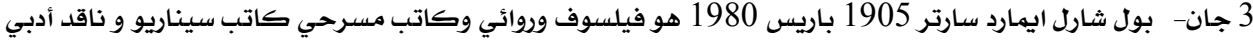

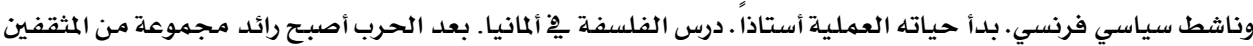




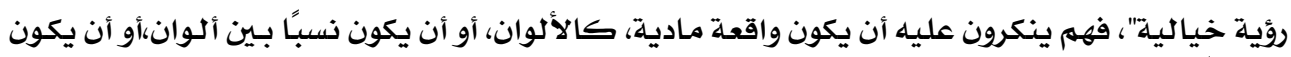

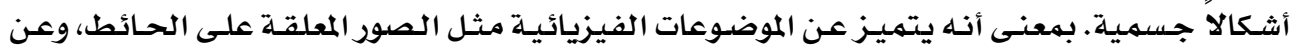

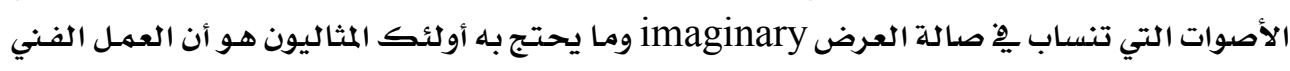

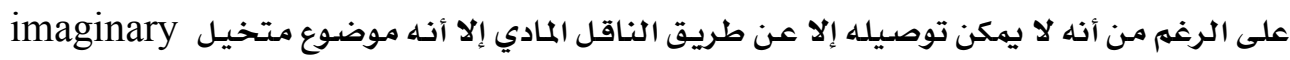
object

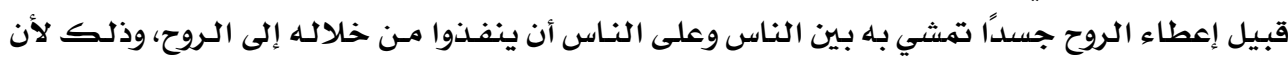

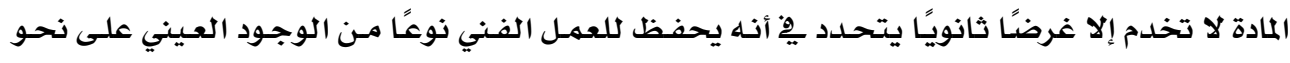

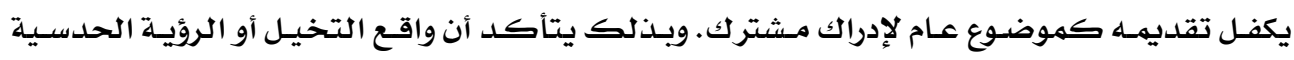

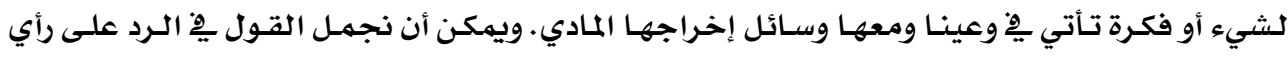

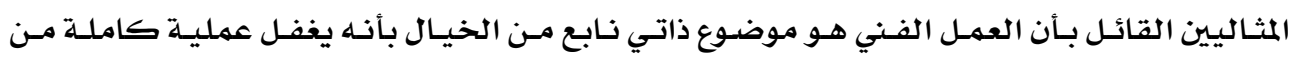

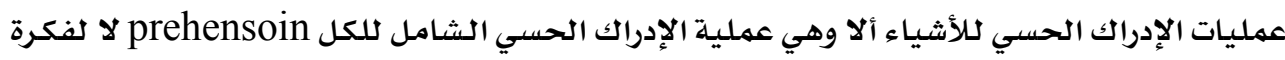

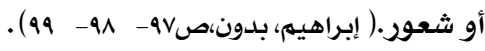

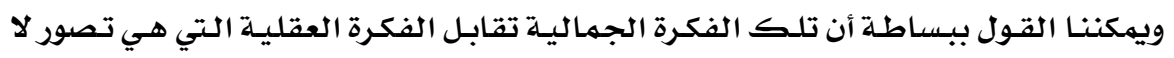

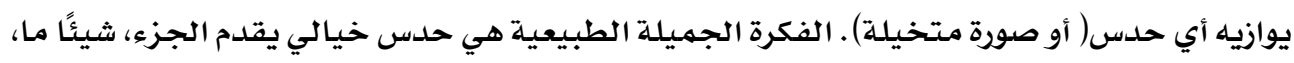

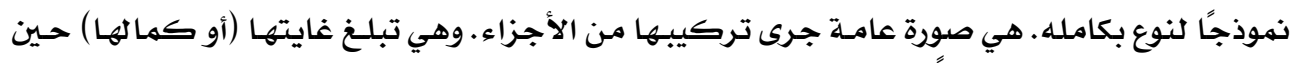

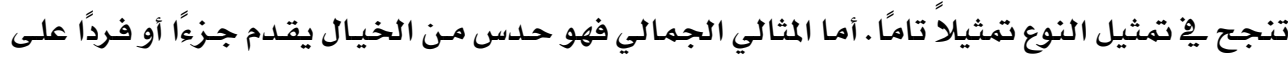

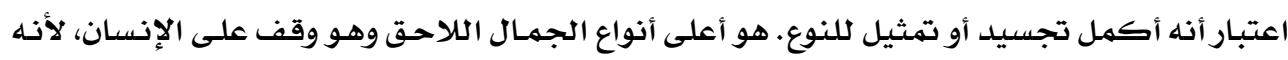

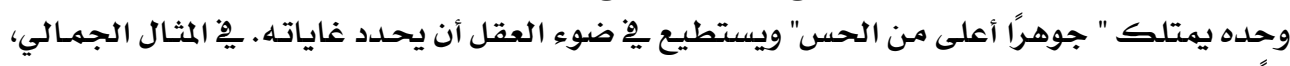

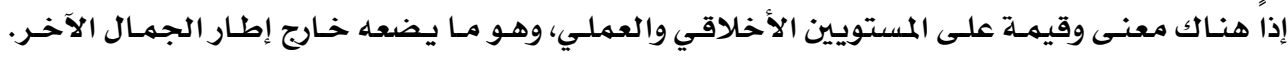

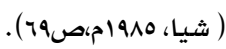

\section{ثانيًا: علم نفس الفن " سيكولوجية الفن"، وعلاقته بالحدس:}

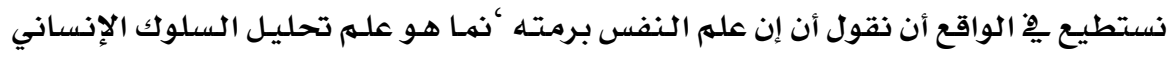

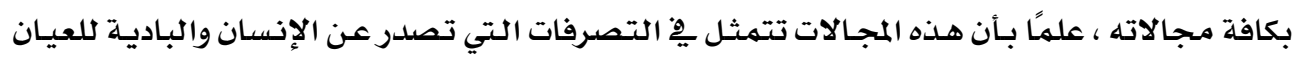

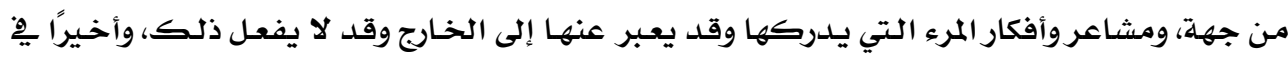

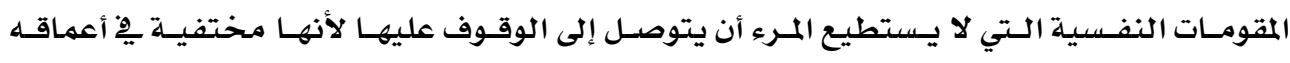

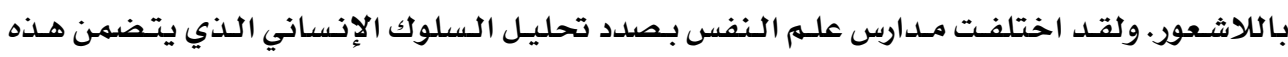

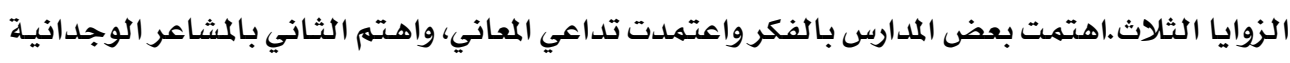

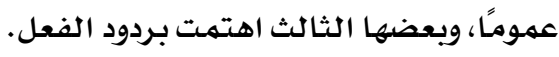


ومن الثابت أن نشأة سـيكولوجية الفـن التجريبيـة قـد واكبـت ظهور علهم النفس التجـريبي

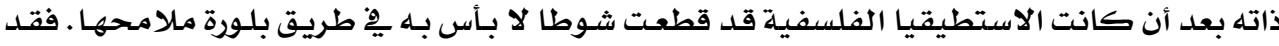

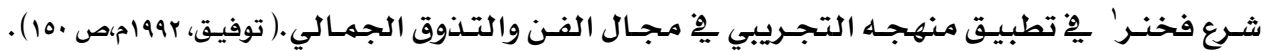

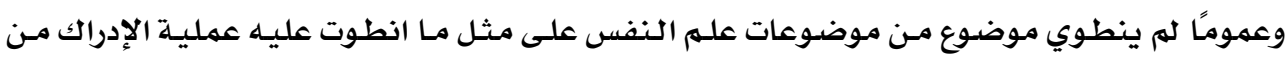

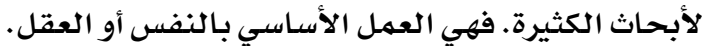

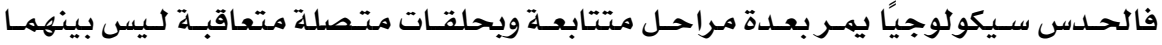

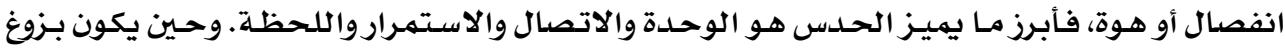

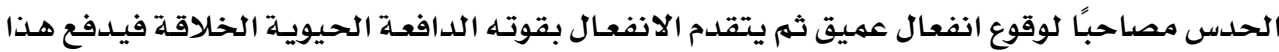

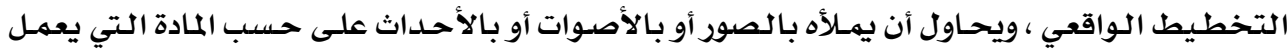

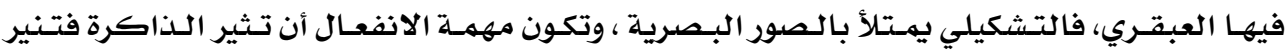

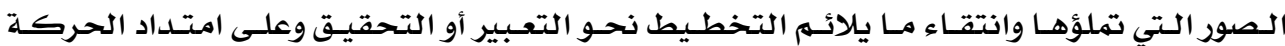

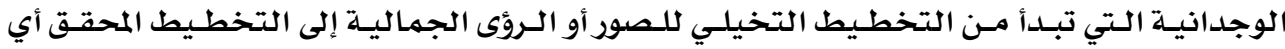

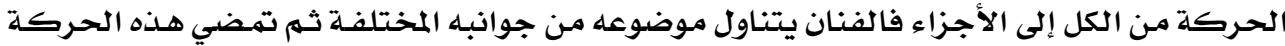

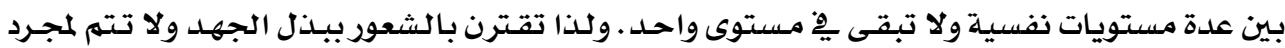

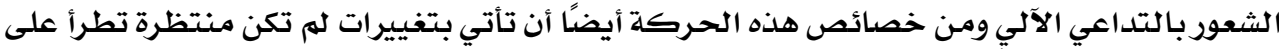

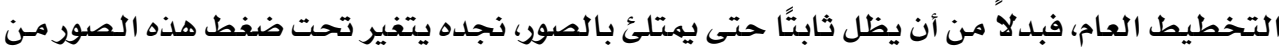

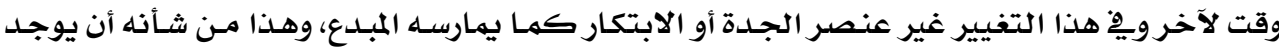
تذبذبًا كحركة البندول

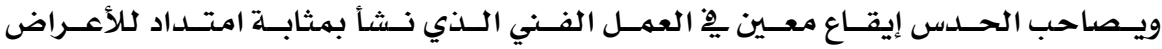

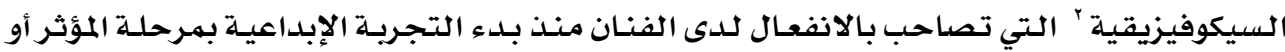

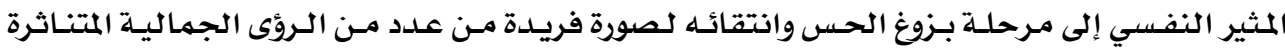

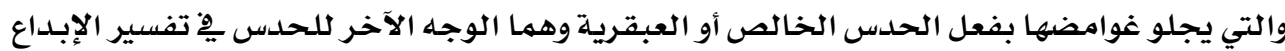
الفني الخلاق.

1 جوستاف فخنر )بالأمانية Gustav Fechner :من مواليد 19 إبريل 1801 ووفيات 28نوفمبر 1887 هو فيلسوف وعالم ألماني، درس الفيزيولوجيا على يد فيبر ثم درس الفيزياء والكيمياء والرياضيات. كان جوستاف من رواد علم

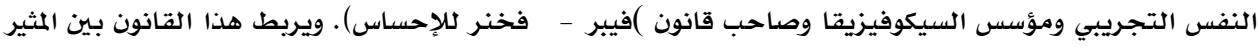

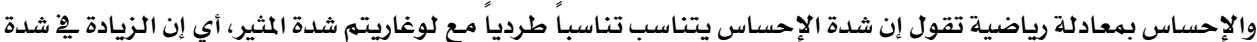
المثير تؤدى إلى الزيادة فِ شدة الإحساس.

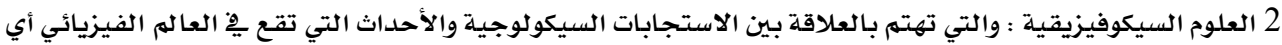

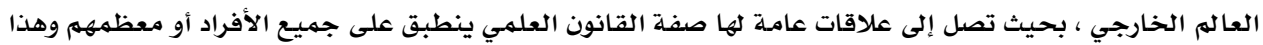
جعلها احد دعائم علهم النفس التجريبي الحديث ، ومن أهم مساهماتها ِِّْ دراسة الفروق الفردية استخدام أسئلة 


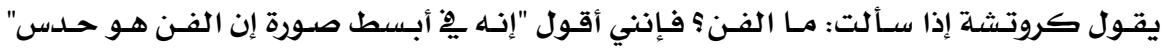

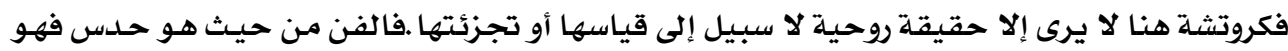

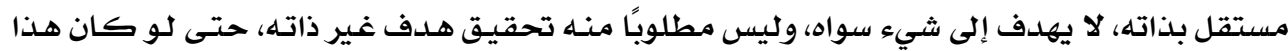

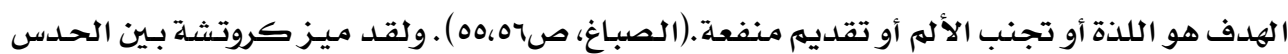

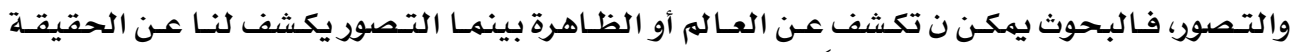

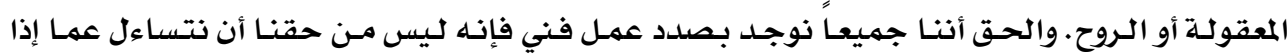

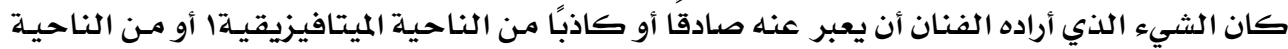

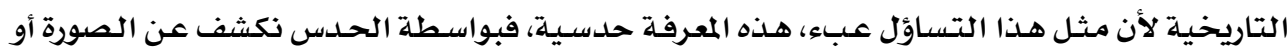

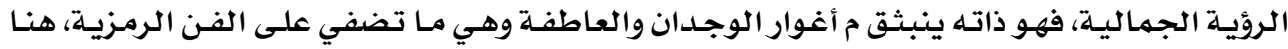

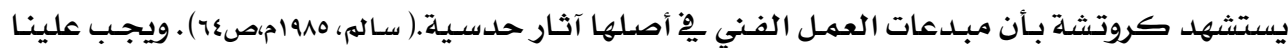

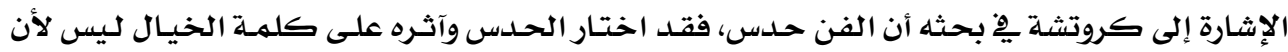

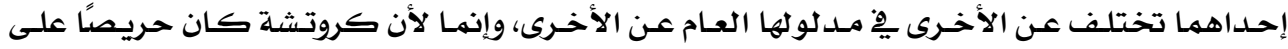

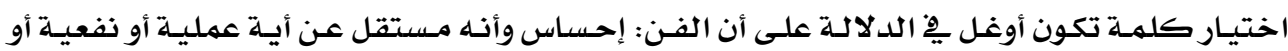

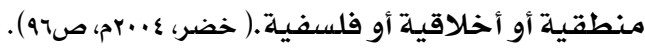

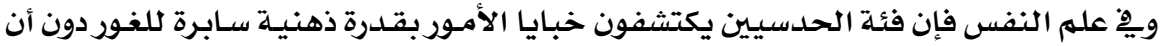

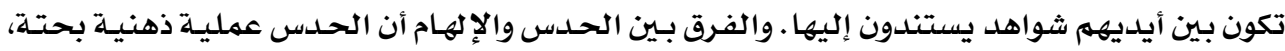

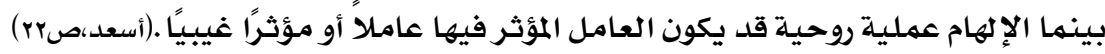

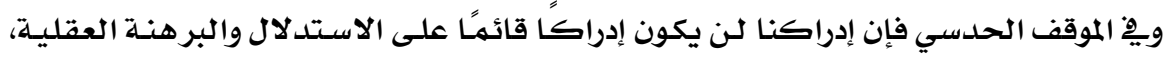

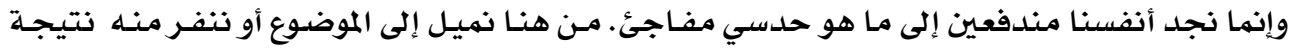

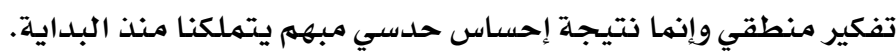

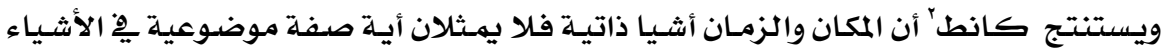

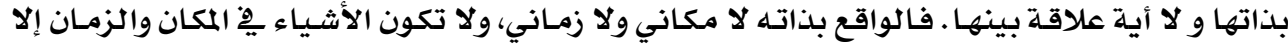

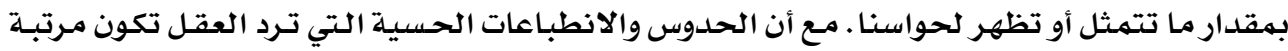

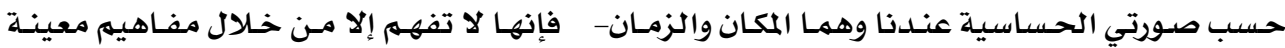

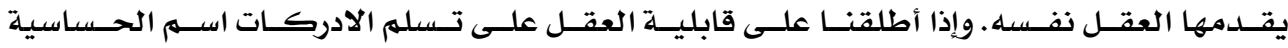
Sensibility

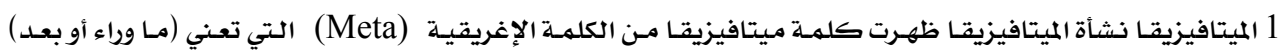

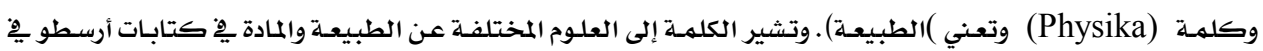
العصور القديمة. 2 إيمانويل كانت بالألمانية 1804 - Immanuel Kant 1724 : و قد يكتب "(عمانوئل كانط)، ) فيلسوف من القرن الثامن عشر ألماني من بروسيا ومدينة كونغسبرغ .كان آخر فيلسوف مؤثر يِّ أوروبا الحديثة يِّ التسلسل الكلاسيكي

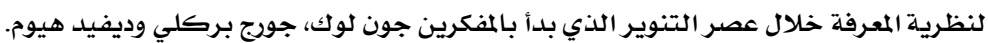




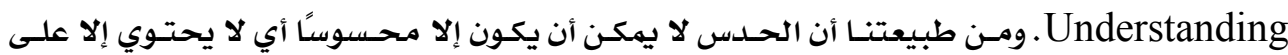

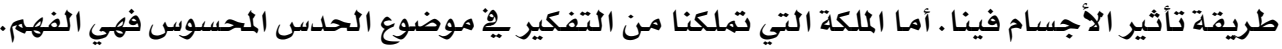

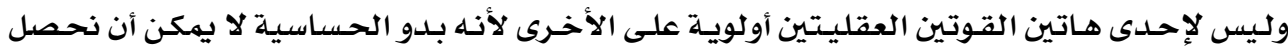

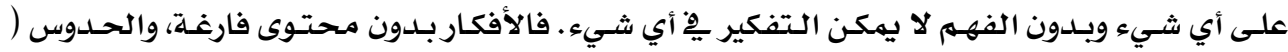

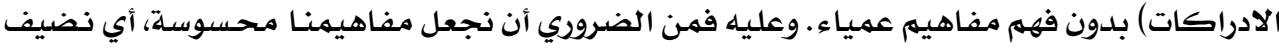

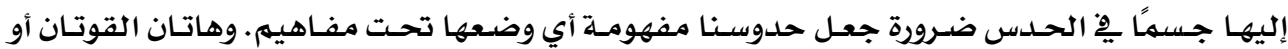

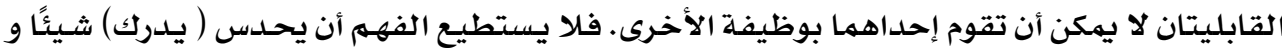

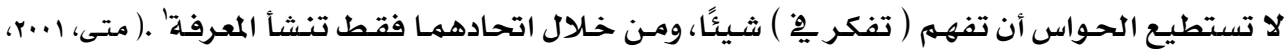

وعمومًا فإِن تنبيه الحس هو متضمن فِ عملية التخيل، وذلك " أنه هِّ التخيل حيث تكون

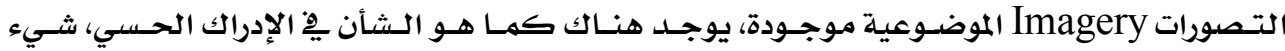

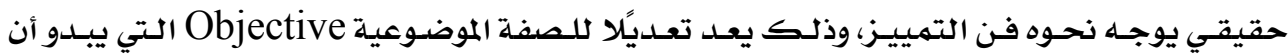

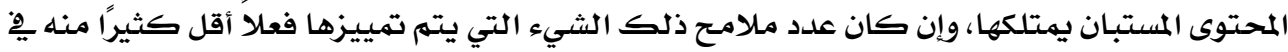

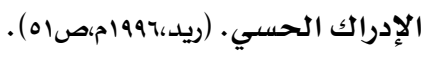

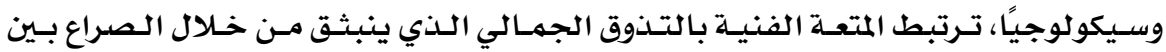

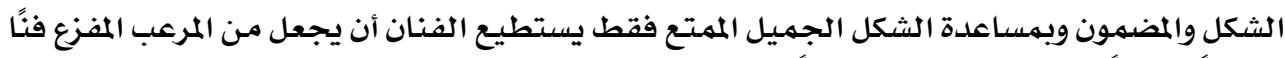

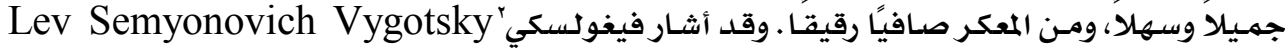

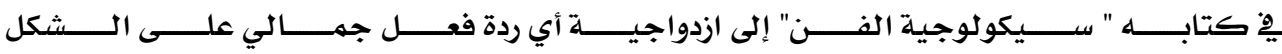
والمضهون.(عبيد،ه. .

$$
\text { ثالثًا : تأثير الحدس على النقد والتذوق الفني }
$$

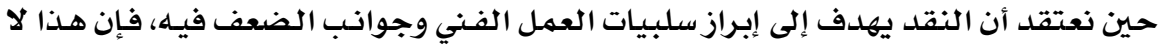

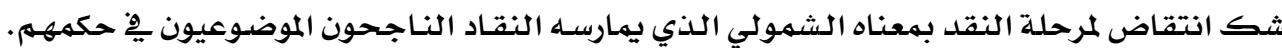

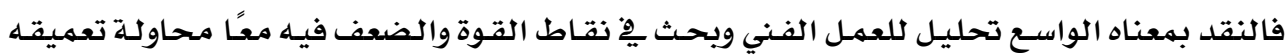

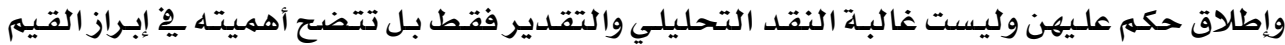

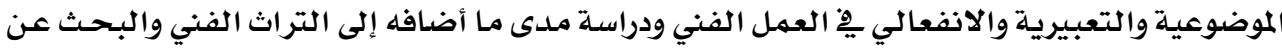

1 المعرفة هي الإدراك والوعي وفهم الحقائق أو اكتساب المعلومة عن طريق التجربة أو من خلال التأمل يِّ طبيعة الأشياء وتأمل النفس أو من خلال الإطلاع على تجارب الآخرين وقراءة استنتاجاتهم، المعرفة مرتبطة بالبديهة والبحث لاكتشاف المجهول وتطوير الذات وتطوير التقنيات.

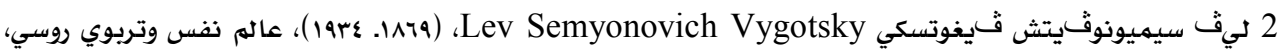
عُرف بأبحاثه ونظرياته المتعلقة بنمو الإدراك لدى الطفل ويالتفاعلات الثقافية الاجتماعية. لهم تعرف أعماله لأسباب

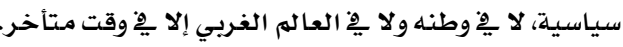




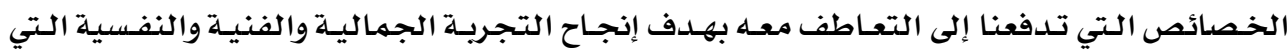
ترتبط بالعمل الفني.

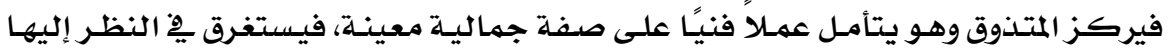

لـذاتها، ويــبح هـدف الفنـان أن يبـقى على اسـتجـابـة المشاهد حسـاسلة تجـاه عملـه الفـني، مـن أجـل أن

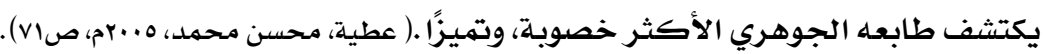

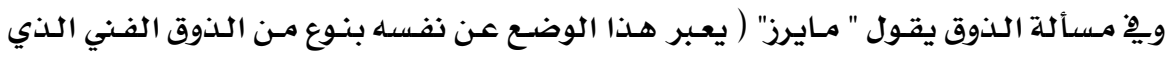

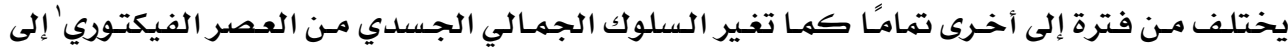
عصرنا الحالي. فنـجد لدينا مشكلتين : كيف ينظر عصر معـين إلى فنـه، وكيف ينظر إلى فن عصر آخر أو إلى ثقافة قد بعلدت من حيـث الزمـان والمكان. وفوق ذلك، فإن الطريقـة الـتي ننظر بها إلى فن

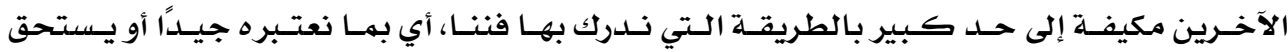

$$
\text { التقدير).( مايرز، 1901، (19،19) ). }
$$

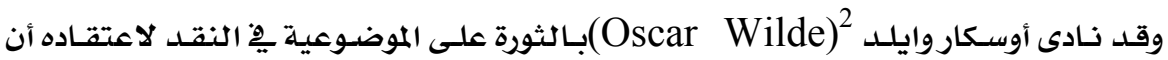

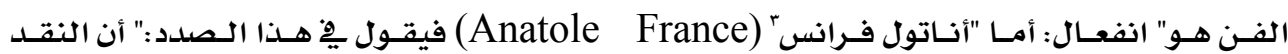
الموضوعي لا وجود لله، لأنه لا يوجد فن موضوعي كذلك، كما كا أن القواعد هي أكثر جمودًا وشكلية

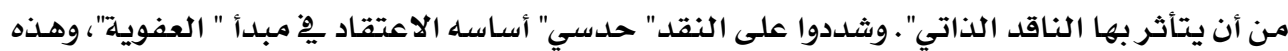

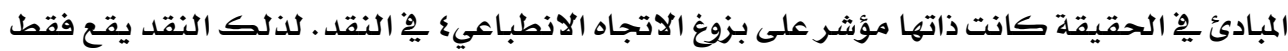

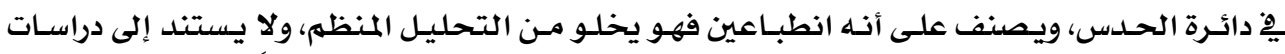
أسلوبية، وكذ لك يستبعد أي اهتهـام بالأثر الفني ذاته، بوصفه موضوعًا متكامـلاً أو تركيبًا ذا معنى،

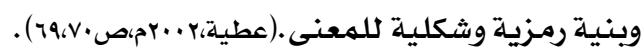

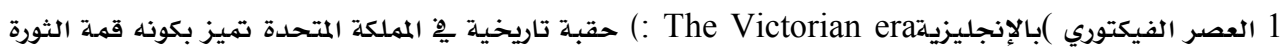
الصناعية ِِ بريطانيا وأعلى نقطة ِِ الامبراطوية البريطانية، وهو يشير إلى فترة حكم الملكة فيكتوريا بين 1837 واعـاعين 19.

2 أوسكار فينغال أوفلاهيرتي ويلزوايلد بالإنجليزيةأية 1854 Oscar Fingal O'Flahertie Wills Wilde 1900

$$
\text { مؤلف مسرحي وروائي وشاعر أنجلو- ايرلندي. }
$$

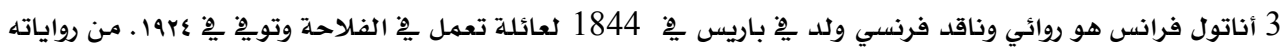

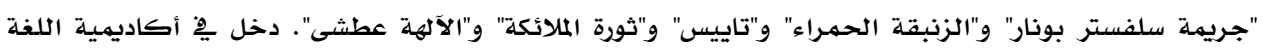

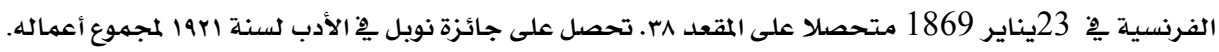
4 انتقلت الانطباعية إلى النقد العربي بتسميات مختلفة (كالمنهج التأثيري أو الذاتي أو الذوقي أو الانفعالي) ، وقد

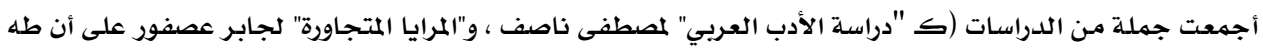

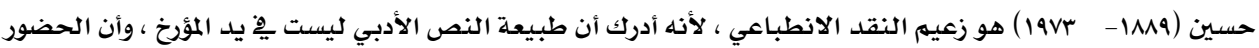
الانطباعي ضرورة يقتضيها النقص الذي يواجه الناقد / المؤرخ. 
إن ما يحدث للمستمتـع أثناء عمليـة التـذوق هـو أن أنهـ يحـاول أن يعسيث مـا قـد عاشـه الفنـان

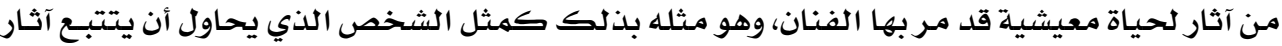

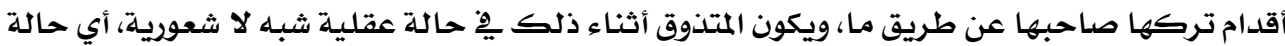

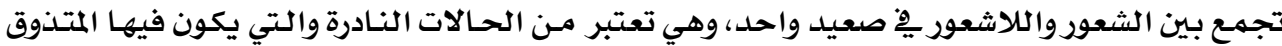
مِّْ حالة حقيقية واقعية.

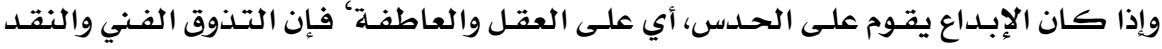

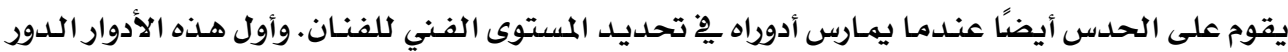

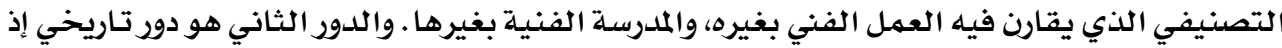

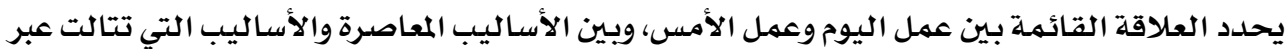

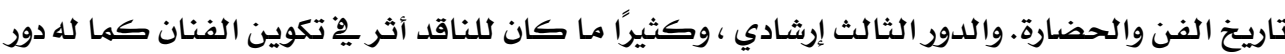

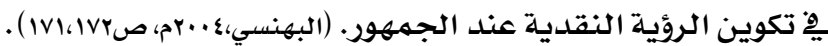

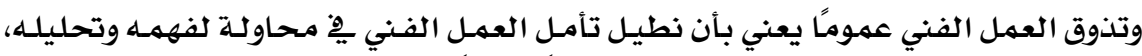

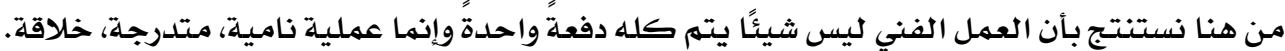
وقد ننتقل إلى عمل فني آخرولكن لا نلبث أن نعود لتأمله أكثر مـن مـرة وتفحصده، والربط بين أجزاؤه

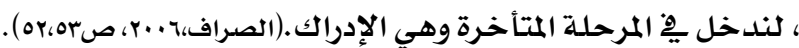

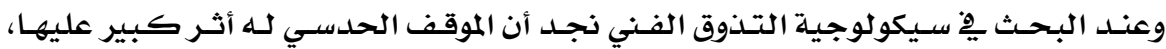
فليس البحث العقلي هو رائدنا يِّا السلوك الجمالي بل هو الحدس أو العيان المباشـر والإدراك المفـاجئ،

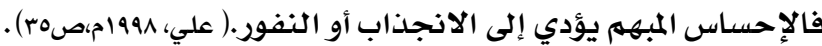

ونلاحظ أن عمليـة التذوق الفـني لا تـتم على مستوى واحسد مـن النـجـاح · بـل تـأتي عـادة على مستويات متفاوتة نتيجة لتفاوت ثقافة المتذذوقين وحسالتهم المزاجيـة والنفسية والاجتهـاعيـة والبيئيـة.

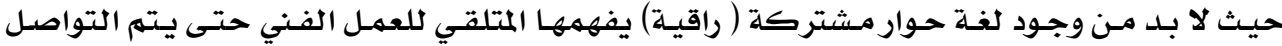

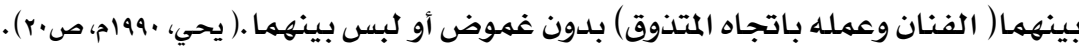
ويشير "عبدالرحمن" إلى العلاقة بين الأساس النفسي الفعـال والتـذوق الفـني فيقول" تـذهب

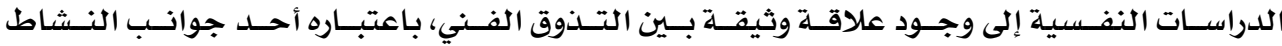
الإنسـاني،وبين مـا يـسهى " الأسـاس الفعـال"Psychic Functional Constitution" بأبعـاده

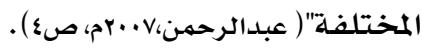

ومهما يجلدر بي التأكيد عليه هو أن الأسـاس النفسي الفعـال لـه أربعـة عناصـر أساسـية، منهـا

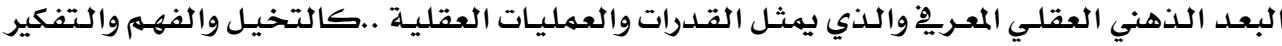

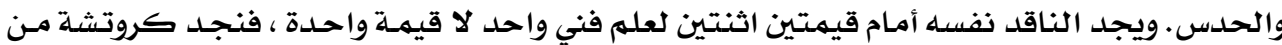

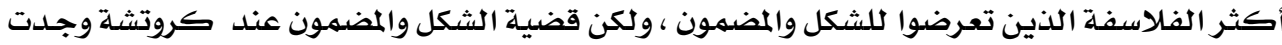

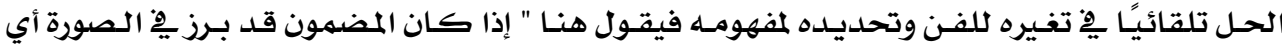

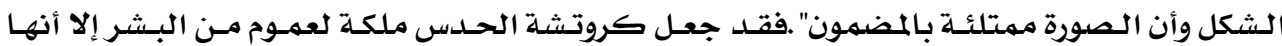




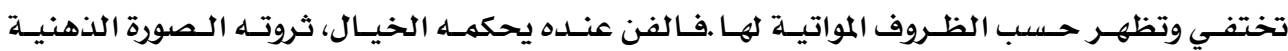

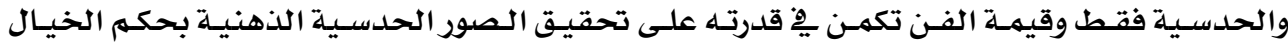

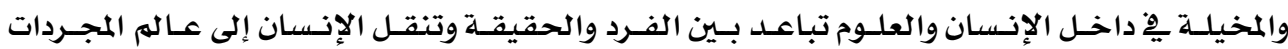

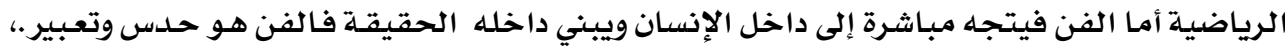

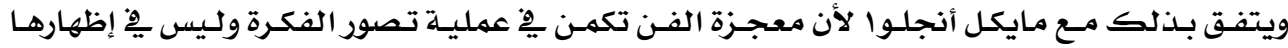

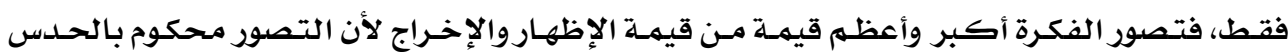

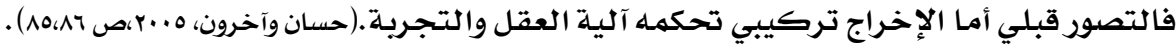

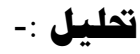

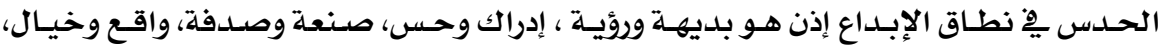

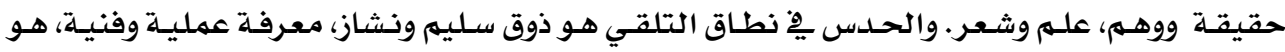

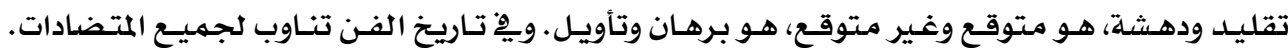

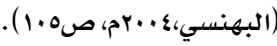

إن الهدف الأول للنقد الفني هو تحقيق الفهم. وهذا يتطلب منـا إتباع طريقة نقديـة للنظر

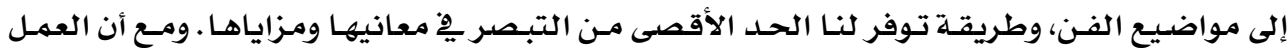

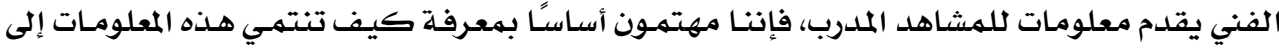
جودة العمل الفني •ولهذا السبب فإن المعلومات الأثرية، والتاريخية، والسير الذاتية عن الفئ الفن والفنـانين

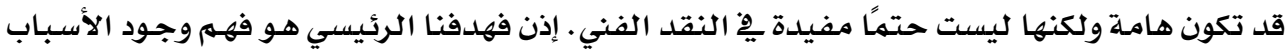

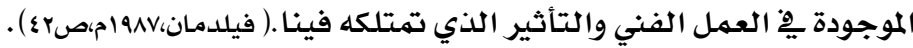

النتائج:

' أ أن الحدس هو وسيلة للكشف عن الرؤى الجمالية والصور الذهنية المتخيلة.

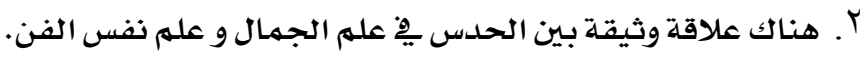

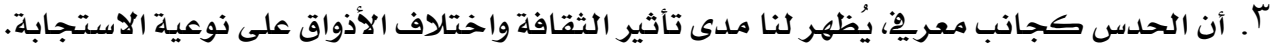

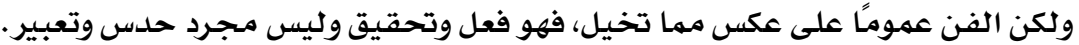

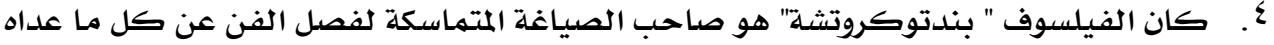
من أنثطة الإنسان. •. يوجد تأثير كبير للحدس على عملية الانسان. النقد والتذوق الفني.

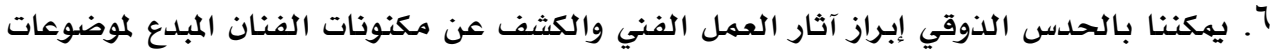

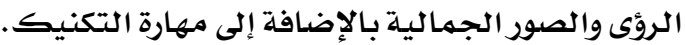
لإنجازاته الفنية الأثر الأكبر على محور الفنون ضمن عصره وخلانيلال المراحل الفنية الأوروبية اللاحقة. 
ا ـ التركيز يِّ تدريس المعايير الفنية والقضايا الجمالية التي لها صلة بالنقد الفني.

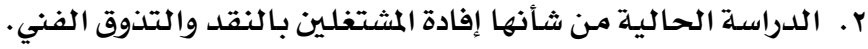

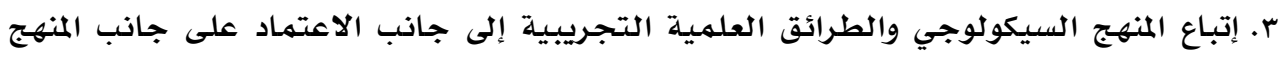
الفلسفي والنقدي يوصل بالعمل الفني إلى مرحلة الإبداع. 


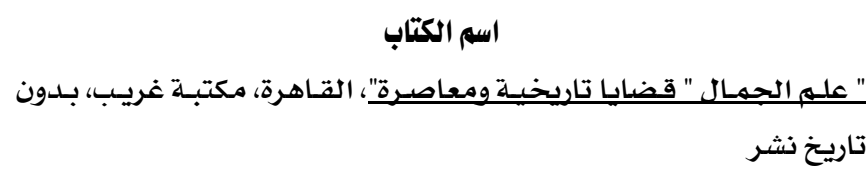

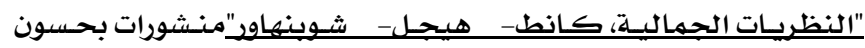
الثقافية، لبنان، 19101م.

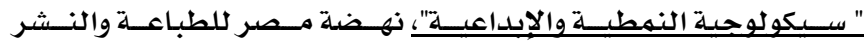
والتوزيع، القاهرة.

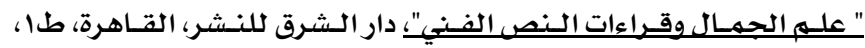
.

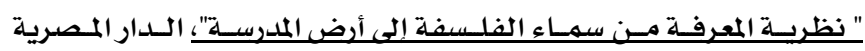

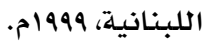

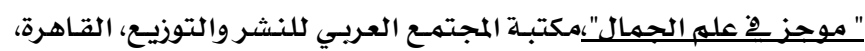
مr..r " الفن والمعرفة الجميلة عند كاسييردي"، دار الوفاء للدنيا الطباعة والنشر،

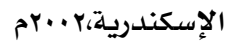

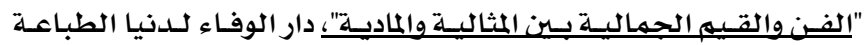

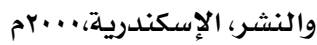

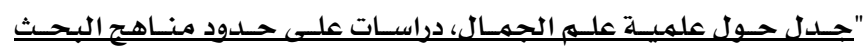

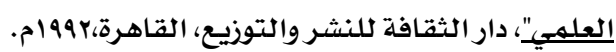

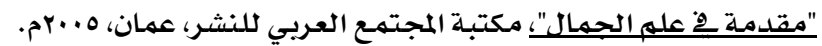

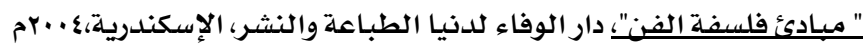

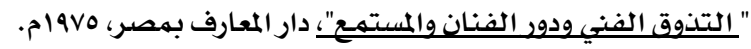

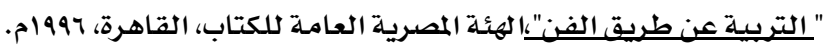
"الإبــاعـاع الفــي"؛ مؤسـسـة شـباب الجامعـة للطبـاعـة والتوزيـع، الإسـكندرية، .

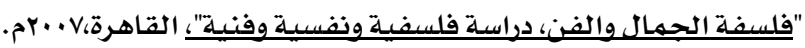

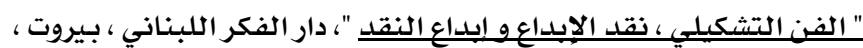

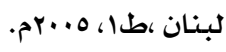

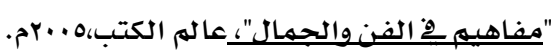

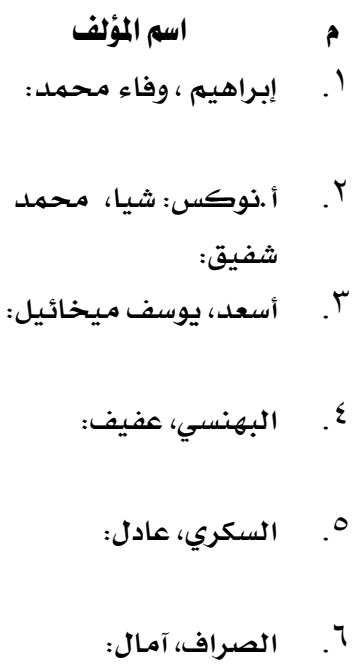




\begin{tabular}{|c|c|c|}
\hline " نقـــ الفنـون"مـن الكلاسيكيـة إلى عصر مـا بعـد الحـداثـة، منشأة المعـارف & 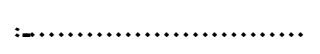 & 11 \\
\hline 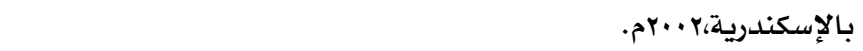 & & \\
\hline "التتذوق والنقد الفني، دار المفردات للنشر والتوزيع، الرياض، 1991م. & علي، أحمد رفقي : & .19 \\
\hline 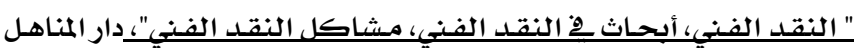 & 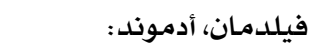 & $r$ \\
\hline للطباعة والنشر والتوزيع،لبنان،ب9919م. & ترجمة :حداد، زياد سـاله: & \\
\hline " الفنون التشكيلية وكيف نتذوقها"، مكتبـة النهضـة المصريية، دار الزهـراء، & 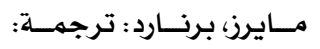 & . \\
\hline 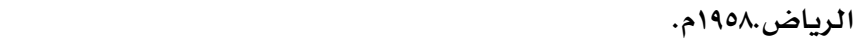 & 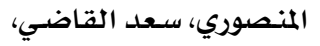 & \\
\hline & مسعدل & \\
\hline 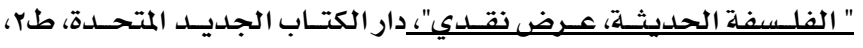 & 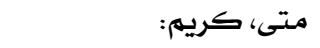 & rt \\
\hline 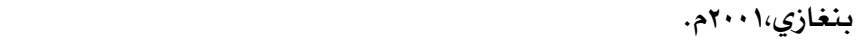 & & \\
\hline " فلسفة الجمال (أعلامها ومـذاهبيها)، دار قبـاء للطباعة والنشر والتوزيـع، & 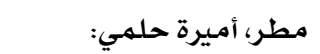 & 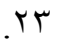 \\
\hline 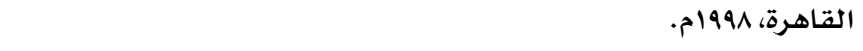 & & \\
\hline " التذوق الفني والســنـما"،دار غريب للطباعة والنشر، القاهرة، 1991م. & يحيى، مصطفى: & $r \varepsilon$ \\
\hline
\end{tabular}

